\title{
A Systematic Analysis on Health, Social, and Political Empower- ment of Women
}

\author{
Liranso G. Selamu*, Mohan S.Singhe \\ Department of Social Work, Mangalore University, Karnataka, India
}

"Corresponding author: Liranso G. Selamu, Department of Social Work, Mangalore University, Karnataka, India. Tel: +0824 228 7276; E-mail:gliranso.2001@gmail.com

Citation: Selamu LG, Singhe MS (2017) A Systematic Analysis on Health, Social, and Political Empowerment of Women. J Nurs Womens Health: JNWH-117. DOI:10.29011/JNWH-117. 100017

Received Date: 08 March 2017; Accepted Date: 01 May 2017; Published Date: 08 May 2017

\begin{abstract}
Women empowerment is an important factor for the uniform growth of nations. Women empowerment including the process of increasing the social, spiritual, political, and an educational, gender or economic strength of individuals and communities that are a label to be the dimensions of women empowerment. Also, the general picture of women empowerment needs to occur along the dimensions of economic, socio-cultural, familial or interpersonal, legal, political, and psychological issues. This article gives a compressive picture of the political, social, and economic women empowerment. Moreover, it throws some of the measures to be taken for the effective implementation of women empowerment.
\end{abstract}

Keywords: Empowerment; Health; Political; Social; Women

\section{Introduction}

Over the past three decades, the discourse on women empowerment in our society has been and continues to be the central theme of international and national debates and discussions on human development. The existing gender disparities in human development have been so acute that global war continues to be waged against various forms of discriminations against women. All too often, women and girls worldwide constantly face various forms of disempowerment in many respects: health, economic, social and politics [1].

A women's traditional position in the society, women's profile in number and quality within the civil service structure is very low. This is greatly attributed to cultural and structural influences or barriers. Culturally, women are associated with maternity and the role they play in a family $[2,3]$. The role of women in procreation said to have created the basis for their discrimination [4]. The society taking a man as a head of a family and a breadwinner bestowed upon him all the decision-making the power of the family including the issues that affect the woman's and girl's personal life. A woman, on the other hand, is expected to be the homemaker, socialize and caretaker under the guidance and support of a man $[2,5]$. Though these structured roles the society framed as the norm are believed to put women in a disadvantaged position, both men and women are well socialized to accept the role assigned to each and lived and continued to live with it. No matter how much a woman participates in production processes, she is identified as "jobless" under the title "housewife" due to the mere fact that she is engaged in unpaid activities [2]. Socially constructed realities created the systemic denial of access to opportunities and resources like education and employment resulted in the lack of self-confidence and low self-esteem, which in turn, constrained women from participation, competition, and engagement in formal paid employment [6].

Cognizant of these facts, the Government of Ethiopia has demonstrated its commitment and moved decisively to advance the agenda first, by affirming gender equality and women empowerment as its major policy area in its Transitional Charter. Secondly, highlighting the importance of engaging women and other excluded and disadvantaged segment of the country's population in its development endeavor, it has issued the first women policy in 1993. The Women's Policy primarily aims at institutionalizing the political, economic and social rights of women [7].

Consistent to these, Ethiopian government created a new structure at the public offices with the Ministerial Restructuring Proclamation No. 691/2010 with the mandate of ensuring increased participation and benefits of women in political, economic 
and social endeavors of the county. Moreover, the structures of government offices were amended to incorporate Gender Affairs Offices at the Department/Directorate level to play a leading role towards strengthening and facilitate gender issues in their respective institutions. Empowering women and ensuring their benefits is also stated to be one of the strategic pillars of the Growth and Transformation Plan (GTP) 2010/2015 of the country. Nationally enacted and amended laws and the international legal instruments adopted at different times aim at changing the social and cultural patterns of conduct of men and women. These instruments are meant to eliminate prejudices, customs and all other practices which are based on the idea of inferiority or superiority of either of the sexes or on stereotyped roles for men and women [8].

Since the adoption of the United Nations Charter in 1945, there are continued international efforts of expanding opportunities towards gender equality and women empowerment. Recognizing women empowerment and gender equality as powerful multipliers of development efforts, International and Regional Governmental (GOs) and Non-Governmental Organizations (NGOs) have been working towards equality and beneficence of women. Millennium Development Goal (MDG) is one of the programs devised by the international community to address the issue of poverty of which gender equality is one [8].

Despite all international, regional and national strategies, governments' political will, legal and structural instruments to increase women's empowerment at all levels in general and in the Federal Civil Service, in particular, barriers are evident in women's participation in decision-making. The tradition of holding the top and middle-level decision-making power still favors men to an overwhelming degree [9-11]. Therefore, the research tried to review international instruments, national laws, and institutional policy frameworks and societal culture and attitudes that have been in place to facilitate and advance gender equality and women empowerment in relation to the civil servant women's asset and capabilities. Besides, government reports and various studies conducted on women empowerment practices in Ethiopian confirm that women participation in political, economic and social endeavors in general and in the civil service structure, in particular, holds low profile[9,10,12,13]. Due to deep rooted and long-lived patriarchal system influence and experience, low status characterizes virtually every aspect of women's lives. This attributes to the socio-economic and cultural status of women, exacerbated by institutional/structural factors that resulted in gender-based division of labor, rights, responsibilities, opportunities, and access to and control over resources. Status of women in employment and decision-making areas, among other things, are main manifestations of gender disparity [9].

Achieving gender equality, however, is a time-consuming process, since it challenges one of the most deeply entrenched human attitudes and practices. Despite the intense efforts of many agencies and organizations and numerous inspiring successes, women in Ethiopia are largely occupying low level and clerical position [9]. The continuity in the status quo of women's engagement in low-level positions is an empirical evidence to support the argument that women empowerment takes far more than changes in law or devising best strategies and policy to change the unjust practices. Though these changes in law, policy and structure are necessary conditions or means, they are not sufficient conditions or end in themselves. Sound public policies and investments are central to achieving MDGs and accelerating economic growth, but they are not enough [14]. Therefore, the research focused on evaluating whether or not the women empowerment practices in the Ethiopia is bring change or not among women of civil servants by exploring the major predictors that impactedprevailing practice on the overall working conditions.

There is also an international initiative with the goal of poverty alleviation by the year 2015, Millennium Development Goal (MDG), which takes women empowerment and gender equity as one of its objective (Goal 3). Taking these and other national, regional and international initiatives into account in addition to demographic feature of women that accounts half of the population, women's important but neglected roles in a society and unbalanced opportunities they experience; it would be of paramount importance to focus on evaluating the practical implementation of the GTP including the strategies and policies enacted toward achieving the targeted social transformation and thereby take timely corrective measures. Moreover, women empowerment and gender equity is one of the prominent human rights and socio-economic development agenda that governments are required to take into account while developing their national programs. Hence, taking the subject as a research agenda would contribute to the national and international efforts towards ensuring social justice, dignity, and worth of the person, which are core values of social work. Research in the sector would help identify not only gaps but also evidence and good practices that need to be scaled up and replicated through changing policies and practices [9].

\section{Theoretical Framework}

The discourse on empowerment is so paramount to human development and alleviation of poverty that it is found in the documentation of over 180 World Bank aided projects [15]. The concept of empowerment has been contested and conceptualized differently by various researchers and advocates. In a preliminary study, [16] conceptualizes 'empowerment and social inclusion' as closely related but separate concepts. Bennett defines empowerment as 'the enhancement of assets and capabilities of diverse individuals and groups to engage, influence, and hold accountable institutions which affect them' (p. 13). On the other hand, 'Social inclusion' has been described as 'the removal of institutional barriers and enhancements of incentives to increase the access of diverse individuals and groups to assets and development opportunities' [16].Narayan (2006) [17] shows the correlation of theoretical 
Citation: Selamu LG, Singhe MS (2017) A Systematic Analysis on Health, Social, and Political Empowerment of Women. J Nurs Womens Health: JNWH-117.

frameworks categorizing economic and human capital, capacity to aspire and organizational capacity under the agency of the poor and openness of institutions; fragmentation and behaviors of dominant groups and state implementation capacity under the opportunity structure. Alsop and Heinsohn (2005) [15] on the other hand hypothesized that agency and opportunity structure in association with the degree of empowerment a person or group experiences. They further explained that the Degrees of Empowerment (DoE) can be measured by assessing

- whether a person has the opportunity to make a choice

- whether a person actually uses the opportunity to choose and

- once the choice is made, whether it brings the desired outcome.

Promoting empowerment also involves examining organizational culture, structure, and processes and identifying where these may conflict with empowerment goals, e.g. in terms of accountability. Efforts should be made to address these organizational issues, through retraining in participatory approaches, increasing the accountability of the organization to beneficiaries, increased flexibility in funding procedures and greater transparency in relationships with communities and organizations [18].

Empowerment theory is an enigma. It also differs across levels of analysis. At the individual level, empowerment includes participatory behavior, motivations to exert control, and feeling of efficacy and control. Organizational empowerment includes shared leadership, opportunities to develop skills, expansion, and effective community influence [19]. Women's empowerment is, therefore, defined as the process of correcting gender disparity in a society that leads to improving the condition and status of women in all spheres (household as well as community level) [20]. It further states that the degree of women's access to and control over material resources (including food, income, land and other forms of wealth) and social resources (including knowledge, power, and prestige) within the family, in the community, and in the society at large. It is a multidimensional concept, which purports to measure a woman's ability to control resources, her ability to choose and control different outcomes, and above all to enhance her selfesteem [20].

Women's empowerment and gender equality discourse, in a historical perspective, has moved through various phases during the past two decades: from Women in Development (WID) to Gender and Development (GAD) [21]. Women's movements developed in the 1970s-demanding political, economic and social equality in society in order to be able to take an active part in development processes and proclaimed the policy Women in Development (WID) [22]. It was further stated that WID clearly recognizes that gender equality and women's empowerment are essential for addressing the central development concerns of poverty and insecurity, and for achieving sustainable, people-centered development. Taking Women's empowerment and their full participation on the basis of equality in all spheres of the society, including participation in decision-making process and access to power as fundamental for the achievement of equality, development and peace, the Beijing Platform for Action identifies gender equality as a goal and mainstreaming gender equality as the strategy of women's overall empowerment (BPfA, 1995). Gender mainstreaming is the (re)organization, improvement, development, and evaluation of policy processes so that a gender equality perspective is incorporated in all policies at all levels at all stages, by the actors normally involved in policy-making [23]. It is also defined as the process of assessing the implications for women and men for any planned action in legislation, policies or programs, in any area and at all levels with the ultimate goal of achieving gender equality [24].

The women's empowerment was measured using different indicators. The Gender-Related Development Index (GDI) is a measurement for gender inequalities in the three dimensions covered by the Human Development Index (HDI), i.e. life expectancy, education, and income. Another tool used is the Gender Empowerment Measure (GEM) which seeks to measure relative female representation in economic and political power. It considers gender gaps in political representation, in professional and management positions in the economy, as well as gender gaps in incomes. The United Nations Human Development Report (2009)[25]classifying under the Low Human Development countries, ranked Ethiopia 85 th in the gender empowerment measure and its components.

However, [26] stipulates that there are four aspects which seem to be generally accepted in the literature on women's empowerment. Firstly, to be empowered one must have been disempowered. It is relevant to speak of empowering women, for example, because, as a group, they are disempowered relative to men. Secondly, empowerment cannot be bestowed by a third party. Rather those who would become empowered must claim it. Development agencies cannot, therefore, empower women the most they can achieve is to facilitate women empowering themselves. They may be able to create conditions favorable to empowerment but they cannot make it happen. Thirdly, definitions of empowerment usually include a sense of people making decisions on matters, which are important in their lives and being able to carry them out. Reflection, analysis, and action are involved in this process, which may happen on an individual or a collective level. There is some evidence that while women's own struggles for empowerment have tended to be collective efforts, empowerment-orientated development interventions often focus more on the level of the individual. Finally, empowerment is an ongoing process rather than a product. There is no final goal. One does not arrive at a stage of being empowered in some absolute sense. People are empowered, or disempowered, relative to others or, importantly, relative to themselves at a previous time. On the one hand, and Degree of Empowerment (DoE), on the other, are assumed to be in a reciprocal relationship. Stating agency is expressed by the asset endowments, the authors clarify that the better a person's as- 
sets and the more favorable their opportunity structure, the higher the framework expects their DoE to be. Similarly, enhancements in a person's DoE are expected to enhance assets and opportunity structure. For example, the higher a woman's assets and the more favorable her opportunity structure, the more likely she is to take effective action against an abusive husband. In taking effective action (achieved choice), the woman might increase her assets (her self-confidence, awareness of women's rights) and also contribute to changes in the opportunity structure (the more women become empowered to act against abusive husbands, the less likely domestic abuse will remain an accepted practice [15].

They further explain the conceptualization of assets and opportunity structure is useful for understanding the underlying reasons and dynamics that shape the degrees of empowerment of different actors, and for identifying activities and strategies for improving people's empowerment. Changes in assets or the opportunity structure are likely to precede changes in degrees of empowerment. Identifying assets and opportunity structure indicators are, therefore, useful for evaluating intermediate impacts of investments in empowerment. Asset and capability indicators are said to be endowments that can be human, psychological, political, economic/material (both physical and financial) and social. Whereas, the presence and operation of the formal (laws and regulations) and informal (norms and customs) institutions determine the opportunity structure, whether individuals and groups have access to assets/resources and whether these people can use the assets to achieve desired outcomes [17].

Most scholars agree that development outcome arises from the interactions of the agency, opportunity structure, and degree of empowerment $[15,17]$. As the dependent variable, development outcome has the hypothetical and reciprocal relations with the independent variables (agency and opportunity variable) and the intermediary variable (degree of empowerment) [15]. If there are able agencies of women and if there is the enabling environment of opportunity structure (both formal and informal) there will be the high degree of empowerment where empowered agencies (development outcome) can be created and vice versa. The framework further explains how development outcomes in turn impact on the agency and opportunity structure to develop to the highest level, as empowerment is the process and both a means and an end in itself. As the authors advise the researchers to contextualize the framework to their specific research objective and mix different variables, this study also took the outcome indicator variables identified on the guideline prepared for implementation of baseline study for women's empowerment by [27]. The guide takes policy and attitude as crosscutting indicators in measuring women empowerment. By measuring the two (policy and attitude) the guideline stipulates nine common women's empowerment outcomes. Policy and attitude can be categorized in the formal and informal relations under the opportunity structure identified by $[15,17]$. Thus, the research used five of the nine common outcomes listed in the guideline, which are found to be relevant to measure development outcome of the civil servants. These are improved women's capacity, women's control over assets, women's participation in decision-making, attitudes of men and women towards women's empowerment and women's satisfaction with the availability and quality of opportunities [27]. This critical review evaluates the impact of women empowerment practice in service organization covered under the study focusing on predictors of women empowerment and gender equality.

As it is observed in any traditional society, the Ethiopian culture takes its roots by highly differentiated femininities and masculinities, and the valuation of masculinity above those of femininity [28]. Ideas about Masculinity and femininity are to be found in all areas of social relations; to make up the patriarchal structures by representation of gender, which is part of the process that makes up cultural notions which individuals come to adopt personal identities as masculine or feminine, and how the content of these are determined [3]. She further explains the most traditional approach to the sexual difference is to see masculine and feminine identities as reflecting the biological structure of bodies, hormones, muscles, and geneses. The discourse of femininity defined women as being contained within the family, and marriage was a central ambition. The feminine ideal was one of selflessness, fragility, and dependence on a husband or father. This involved the absence of work outside the home for money. Philanthropy, which might appear as work outside the house, did not transgress the feminine ideal because it did not involve payment. Masculinity, on the other hand, involved an orientation to the outside world, beyond the family and household. Further explains women faced a dilemma over the stigmatizing consequences if they entered activities in the 'male' or 'public' sphere [3].

Furthermore, masculinity entails assertiveness, being active, lively and quick to take the initiative. Femininity entails cooperativeness, passivity, gentleness and emotionality. Training in one or the other set of gender attributes is considered to start from birth in every aspect of their lives, encouraged or discouraged from greedy feeding. Socialization proceeds with a set of rewards and punishments, ranging from changes in tone of voice to physical chastisement [2]. Although the setup of sex-role stereotypes varies between cultures, all share women's inferior position in common. Sex-role stereotypes are well established in early childhood. The male child is valued more than the female child by the parents, siblings and the community. In other words, traditional practices and religious norms discriminate women from infancy throughout their lifetime [29]. Therefore, educating girls were also seen as Westernizing, undermining men's natural superiority [29]. Given the time frame and context of Ethiopian society, women rarely deviated from the norm. The risk of becoming an outcast in their community contributed to their compliance to practices that directly undermined their own rights. On the other vein, the existing socio-cultural practices played a great role not only for women's oppression but also were 
Citation: Selamu LG, Singhe MS (2017) A Systematic Analysis on Health, Social, and Political Empowerment of Women. J Nurs Womens Health: JNWH-117.

a major obstacle to their empowerment [29]. Such societal norms are likely to impede women's access to full citizenship as they prescribe different treatment for men and women. Deeply gendered socio-cultural norms, sex-stereotypes, harmful traditional practices, and patriarchal ideologies limit women's chances for successful educational pursuits and confine their rights. Women in Ethiopia traditionally have been consigned to strict societal rules that limited their activities to household chores and childcare activities while men perform activities outside the home. In particular, women in the rural areas are heavily burdened in the household as they are expected to wake up so early, to clean, get children ready for school, do the cooking, washing and sacrifice their career and aspirations [29].

As culturally imposed meanings are deep-rooted, taken-forgranted, unexamined and dominant while experimentally-acquired meanings are closely felt, experienced, intimate and uniquely interpreted" [30], and due to the long-lived patriarchal structures in the country women in Ethiopia are highly socialized to accept and live by the rules and regulations that defined their responsibilities and status, that obviously is their subordination. As a result, they lined out that how women's subordination is the unconscious process, meaning that women do not realize that they willingly play into the hands of patriarchal rule and powers. They cannot realize that because patriarchy is overwhelming and embedded in every part of the societal fabric from schools to workplaces, to societal gatherings and families. That is to say, customary and religious laws, which are based on the ideologies of the patriarchal order largely, promote women submissiveness.

Likewise, in many developing countries, women in Ethiopia face structural and political barriers that hinder their rights to equality in the social, economic and political sphere. In addition to cultural and customary barriers, negative attitudes and sexstereotyped perceptions as reviewed earlier; gender inequality has also been attributed to structural and political barriers [29]. Ayrorit identified four shortfalls in this regard, that include lack of accessibility and affordability to major information sources and bureaucratic barriers preventing access to information to women. For example, access to the radio, TV and the internet remains low in Ethiopia, particularly in rural areas which, she explains, makes many women ignorant of the existence of laws that recognize their rights and can be invoked for their protection.

Finally, and most importantly, is the failure to actively engage men in gender equality work. Gender has long been seen as women's responsibility and gender equality as women's agenda. This has been demonstrated in various occasions related to gender. Therefore, Ayrorit suggested active engagement of men is crucial for the promotion of gender equality in a sustainable manner as gender equality is not possible without the active involvement and support of men. It is stated that "Unless men's practices, attitudes, and relations change, efforts to promote gender equality will face an uphill struggle" [31].

\section{Conclusion}

Most of the studies carried out so far regarding the women empowerment in Ethiopia show a positive trend. Women access to health care, socioeconomic development and independent decision making. However, the general framework of women empowerment is so far not critical analyzed in detail. Some report suggested that women empowerment can also affect the social, cultural balance exists in the country. However, overall, the positive effect of women empowerment is overwhelming the negative effect in the country. Thus, conducting periodic gender audit to review the implementation of plans developed to realize women empowerment/ gender equality and taking appropriate actions are mandatory. Organizing and ensuring the participation of politicians in general and leaders of Gender offices in particular are recommended to be instrumental in the processes of women empowerment.

\section{References}

1. UNDP (2010) Convention on the Elimination of All forms of Discrimination against Women.

2. Lindsey L (2005) Gender Roles: A Sociological Perspective. In:4, Pearson Education Inc, Upper Saddle River, NJ.

3. Walby S (1990) Theorizing Patriarchy. Basil Blackwell Ltd, Oxford, UK. Pg. No: $1-123$.

4. CEDAW (1979)United Nations Population Information Network (POPIN) UN population division, department of economic and social affairs, with support from the un population fund (UNFPA). Population Fund, Task Force on ICPD Implementation, 220 East 42nd Street, New York.

5. Best, Williams, Matsunoto (2001) On Measuring Women Empowerment: An Example of Indian Tribes. Scottish Church College, Kolkata.

6. UNFPA (2005) Gender Inequality and Women's Empowerment Ethiopian Society of Population Studies, In-depth Analysis of the Ethiopia Demographic and Health Survey, Addis Ababa, October 2008.

7. Women's Policy (1993) Engendering development: Through equality in rights, resources, and voice. World Bank Policy Research Report, Oxford University Press, Oxford.

8. Bayle E (2013) Women Empowerment Practice in Ethiopia. Addis Ababa, Ethiopia.Pg.No: 1-152.

9. APRM Report (2011) Accounting for spousal abuse in Ghana. Master's Thesis, Department of Psychology, Norwegian University of Science and Technology (NTNU), Trondheim.

10. MoFED (2012) National Gender Responsive Budgeting Guidelines: for mainstreaming Gender in the Programme Budget Process. Addis Ababa, Ethiopia.

11. Syed J (PMWASS) (2004) Reconstructing gender empowerment. Women Studies International 33: 283-294.

12. Folbre N (2008) Measuring care: Gender, empowerment, and the care economy. Journal of Human Development 7: 183-199.

13. Tarik (2012) Report on the Selected Practices on Gender Mainstreaming Addis Ababa, Ethiopia. 
Citation: Selamu LG, Singhe MS (2017) A Systematic Analysis on Health, Social, and Political Empowerment of Women. J Nurs Womens Health: JNWH-117.

14. UN (2008) Achieving the Millennium Development Goals in Africa: Recommendations of the MDG Africa Steering Group.

15. Alsop R and Heinsohn N (2005) Measuring Empowerment in Practice: Structuring Analysis and Framing Indicators, World Bank Policy Research Working Paper 2310. APRM Ethiopia Country Report 2011. Pg. No: 289-290.

16. Bennet $L$ (2002) Using empowerment and social inclusion for pro-poor growth: A theory of social change (Background paper for the Development Sector Strategy Paper. Preliminary incomplete draft) World Bank, Washington, DC. Pg. No: 1-38.

17. Narayan PD (2006) Measuring Empowerment: cross-disciplinary perspectives, Oxford University Press, ND.

18. Oxaal and Baden (1997) Gender and Empowerment: definitions, approaches and implication for policy, Briefing prepared for the Swedish International Development Cooperation Agency (Sida) BRIDGE Institute of Development Studies, University of Sussex, Brighton.

19. Zimmerman M (1990)Taking Aim of Empowerment Research: On the Distinction Between Individual and Psychological Conceptions. American Journal of Community Psychology 18: 169-177.

20. UNFPA (2008) Human Development Report Gender empowerment measure and its components. Oxford University Press, New York.

21. Fikremarkos M (2009) Women and Girls and HIVIAIDS in Ethiopia, An Assessment of the Policy and Legal Framework Protecting the Rights of Women and Girls and Reducing Their Vulnerability to HIVIAIDS. UNFPA. Pg. No: 1-72.

22. Ryan B (2007) Gender Mainstreaming and Empowerment Concepts studied in a development cooperation programme in Kenya supported by Sweden, Master Thesis in Africa and International Development Centre for Africa Studies, Göteborg University School of Global Studies. Centre for African Studies. Pg No: 1-65.
23. Council of Europe (1998) Reflections on the Concept and Practice of the Council of Europe Approach to Gender Mainstreaming and Gender Equality. Maryland, USA.

24. United Nations (2003) Human development report: Cultural liberty in today's diverse world. Oxford University Press, New York.

25. United Nations Human Development Report (2009) Convention on the Elimination of All forms of Discrimination against Women.

26. Mosedale S (2005) Assessing Women's Empowerment: Towards a Conceptual Framework. J Int Dev 17: 243-257.

27. Norway C (2009) Guidelines for the Implementation of Baseline Study for Women Empowerment Programmes funded by Norad.

28. Biseswar I (2011) The Role of Educated/Intellectual Women in Ethiopia in the Process of Change and Transformation towards Gender Equality(1974-2005) University of South Africa. Pg. No: 1-272.

29. Ayrorit MY (2013) Affirmative Action for Women in Higher Education and the Civil Services: The Case of Ethiopia. Dissertation, University of Amsterdam.

30. Kasper in Biseswar (2011) Resources, agency, achievements: Reflections on the measurement of women's empowerment. Swedish International Development Agency: Stockholm. Sweden.

31. Ruxton in Ayrorit (2013) Women, work and empowerment in global era. IDS Bulletin 35: 117-120. 